\title{
Influence of cement content on the thermal properties of compressed earth blocks (CEB) in the dry state
}

\author{
N. Zakham ${ }^{1,2}$, Y. El Rhaffari ${ }^{3}$, A.Ammari ${ }^{1}$, M. Cherraj ${ }^{1,2}$, H. Bouabid ${ }^{1}$, K. Gueraoui $^{1,2}$, A. Samaouali ${ }^{3}$, A. Mzerd $^{3}$ \\ ${ }^{1}$ Mohamed V University, Department of physics, Laboratory of Mechanics and Materials, Rabat, Morocco \\ ${ }^{2}$ Mohamed V University, Department of physics, Team of Modeling and simulating in Mechanics and Energetic, Rabat, \\ Morocco \\ ${ }^{3}$ Mohamed V University, Department of physics, of thermodynamics, Rabat, Morocco
}

\begin{abstract}
The Compressed Earth Block (CEBs) is one of the kinds of building materials which stabilized by cement. Soil is a basic component, a renewable, non-toxic and natural resource. Samples must be stabilized with a limited percentage of cement so that samples do not lose their natural properties including thermal comfort and on other hand offer high mechanical resistance. The objective of this work is to study the effect of cement content on thermal behavior of the building material of CEBs in the dry state, by studying variation of temperature with time, and measuring thermal conductivity and the specific heat, with respect to the various cement ratios added to the samples. This study is mainly an experimental and numerical, to determine how the thermal behavior evolves with the cement content in the samples CEBs. The soil was extracted from the famous city Fez in Morocco, Fez is known for its several historical monuments and buildings. After determining its granulometry and other specific characteristics, the CEBs are made by mixing soil with cement. The samples are put in plastic bags for two weeks, then removed the plastic bags from the samples and let them to dry again for an additional two weeks away from direct sun. The samples CEBs are taken cylindrical form ( $8 \mathrm{~cm}$ diameter with an average height of $12 \mathrm{~cm}$ ).

The experimental method consists of a hot ring for which a numerical modelization was developed to fit the mathematical equations of heat diffusion and the boundary conditions. For the numerical model Bouabid and Cherraj have developed numerical model which allow, with a good accuracy, to quantify the evolution of the thermal behavior of the earth material in function of cement content.

Indeed, the study provides information on the influence of the cement percentage on the thermal behavior of the samples CEBs, the thermal behavior of samples increase with increase cement content.
\end{abstract}

\section{Nomenclature}

r: Along the radial coordinate.

z: Along the axial coordinate.

$\mathrm{T}$ : Temperature $[0 \mathrm{C}]$.

$\mathrm{T}$ : Heating time $[\mathrm{S}]$.

$\rho:$ Volume density $[\mathrm{kg} / \mathrm{m} 3]$.

$\mathrm{Cp}$ : Specific heat [J $/ \mathrm{kg} . \mathrm{K}]$.

K: Thermal conductivity [W/m.k].

-

$q$ : Heat flux [ W.m2].

C(D): The magnitude.

D: The variable of cement content.

C0: Value of the quantity when $\mathrm{D}=0$. The optimal value of ' $\mathrm{C}$ ' corresponds to the point of inflection of the curve of the evolution.

$a_{D}$ : The Saturation of cementation limit.

$\mathrm{n}$ : Degree of variation $(\mathrm{n}=3)$.

$\mathrm{b}_{\mathrm{D}}$ : Constant introduced to approximate the limit (asymptote) by inferior value.

\section{INTRODUCTION}

In order to ensure obtain thermal comfort in the building, special attention must be in the selection of building materials, and when we identify the properties of building materials used, we can choose the best to get the thermal comfort.

The earth material is considered a construction material which has been used to build thermally comfortable structures in many regions around the world for thousands of years, it is one of the most important and most common in the world, it is suitable as building material and has low thermal properties, and the compressed earth blocks are model for that. In our study, we have chosen compressed earth block stabilized (CEBs) [1, 2] , we carried out experimental and numerical study to understand thermal behavior of the samples compressed earth block stabilized (CEBs) in the dry state when cement is added to it at different percentages $(0 \%, 4 \%, 7 \%$ and $10 \%)$. Adding cement to the samples CEBs improves their performance and durability, where we added small amounts of cement $(4 \%, 7 \%$ and $10 \%)$ to the samples, the samples are compressed by machine with pressure $2 \mathrm{MPa}$.

There are many factors impact to thermal behavior of the samples, such as the humidity in building materials. Our samples have been dried because we need just to study the effect of cement only on the thermal behavior of the samples in dry state.

The instrument for measure thermal conductivity in the experimental study we were used the hot ring method, 
the hot ring technique is transient method of measurement of the thermal conductivity. The principle of measurement is by a ring at the center of which the temperature rise is measured, the measurement of the temperature rise at the center of the ring allows to determine the thermal conductivity of the samples CEBs [3].

\section{The materials used}

The materials used for making samples are soil, cement and water. The main component of the samples is soil, soil has been taken from in Fez in Morocco, usually use in traditional building materials in Fez, this the city of the most important cities of Morocco which is famous for its history and its buildings ancient and antique. The granular fraction of the earth $\mathrm{Fez}$ is $8 \%$ clay, $28 \%$ gravels, $12 \%$ silt and the sand (main constituent) is composed of $30 \%$ large sand and $22 \%$ fine sand. The samples (CEBs) are made by mixing earth with cement and water, four ratios of cement stabilizers were used $(0,4,7$, and $10 \%)$, the cement type CPJ35 Portland. The mixture is distributed in molds and pressed by a specialized machine for making compressed earth block with pressure $2 \mathrm{MPa}$, all the samples of $\mathrm{CEBs}$ took cylindrical forms, the height of samples $(12 \mathrm{~cm})$ and the diameter $(8 \mathrm{~cm})$, and left drying the samples in the open air for a month, away from direct sun.

\section{Experimental Procedures}

After making samples, each sample was divided to two parts, and was dried from the water content (so that the water content becomes in each sample $0 \%$ ), the drying process has been carried out in an electric oven at temperatures of $60{ }^{\circ} \mathrm{C}$ up to the stabilization of the mass of the samples. The drying time was 72 hours, it is very important to dry the samples before the determination of the thermal behavior.

For thermal measurements, there many methods developed for the determination of thermal behavior, in this study used method of hot ring and the measurement of the thermal behavior of the samples is based on heat transfer in regime unsteady. The hot ring method power supply by a hot ring probe (the slab of kapton of the hotring apparatus) to measure the thermal conductivity and to estimate the thermal diffusivity of the samples, the principle of the slab of kapton the hot-ring apparatus is placed between two pieces of the sample in the middle, and then we inject current into the ring to generate a heat flux, this heat flux dissipates in the material and arrives after a certain time in the center of this ring, where the measurement is made. There is therefore a time lag between the heating and the measurement, which makes it possible to identify by a mathematical algorithm the thermal diffusivity of the samples (Figures 1 and 2) [914].

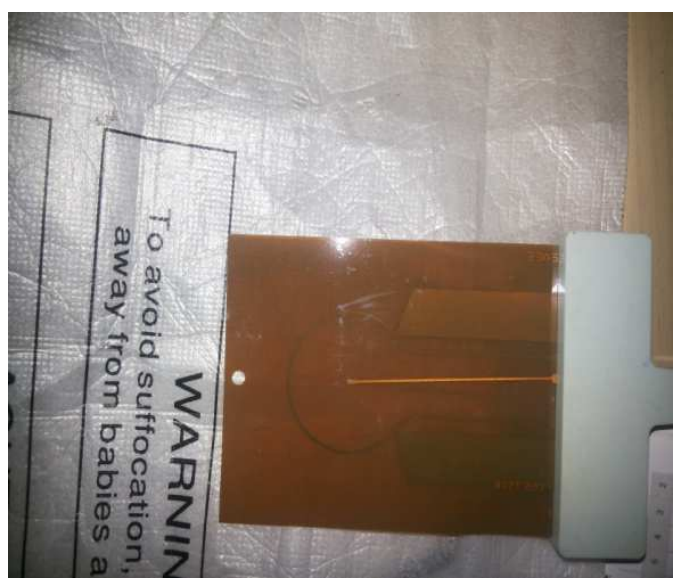

Fig 1. The slab of kapton of the hot-ring apparatus.

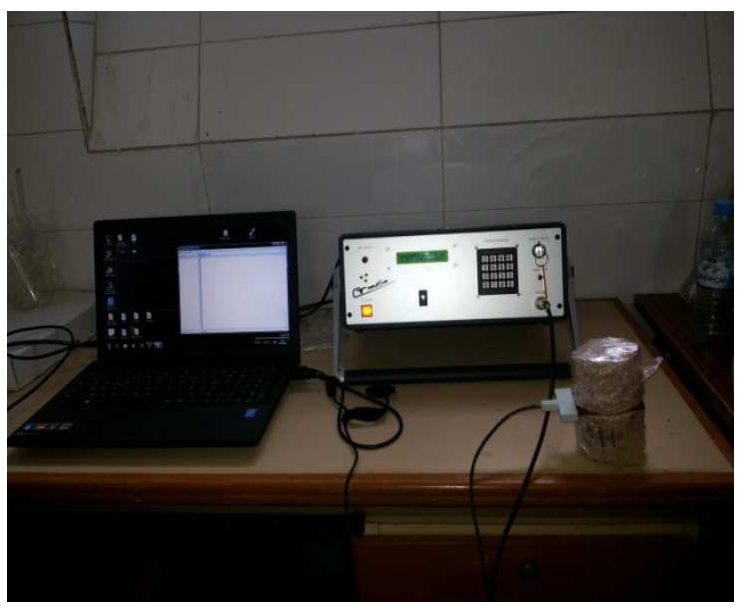

Fig 2. The hot-ring apparatus.

Total heat transfer be determined using the timedependent heat equation, which for flow in two dimensions can be written as:

$$
\rho C_{p} \frac{\partial T}{\partial t}=k \frac{1}{r}\left(\frac{\partial}{\partial r}\left(r \frac{\partial T}{\partial r}\right)\right)+k \frac{\partial^{2} T}{\partial z^{2}}+\dot{q}
$$

where $\mathrm{t}$ is time, $\rho$ is the material density and ${ }^{C}{ }_{p}$ is the specific heat capacity, the energy required to heat up one kilogram of a given material by one degree, where $\dot{q}$ is the heat flux (heat transfer per unit area), $\mathrm{K}$ is the thermal conductivity (heat transfer per unit length for a temperature difference of one degree), $\mathrm{T}$ is the temperature, $\dot{q}$ Heat flux [4-6].

The Initial conditions are:

$t \leq 0 ; T(\mathrm{r}, \mathrm{z}, \mathrm{t})=T_{\infty} ; \forall \operatorname{rand} \forall z$

for all $\mathrm{r}$ and $\mathrm{z}$ when:

$t \leq 0, T(r, z, t)=T_{\text {init }}$

With the following boundary conditions:

For $r=0, \forall z \frac{\partial T}{\partial t}=0$;

$Z=-\frac{H}{2}$ and $+\frac{H}{2} ; T=T_{\infty}$

For $\forall \mathrm{Z}$ and $\mathrm{r}=\mathrm{R}, \mathrm{T}=\mathrm{T}^{\infty}$; 


$$
r \rightarrow \infty \text { or } z \rightarrow \infty T(r, z, t)=T_{\text {init }}
$$

\section{Numerical modelling}

The modeling used for the determination of thermal behavior of the samples CEBs is essential to predict the real thermal behavior of the samples when add a cement. The main characteristic of the proposed model is that it was developed in approximations numerical results with experimental results, Bouabid and Cherraj have developed numerical model which allow, with a good accuracy, to quantify the evolution of the thermal properties of the earth material in function of cement content [7-8]. According to figure 3 , one finds that in the areas I and III there is no presence of significant improvement of the magnitude ' $C(D)$ ' in function of the stabilization ' $\mathrm{D}$ '. Whereas Zone II presents a clear increase of the thermal conductivity and specific heat to the cement content (Figure 3).

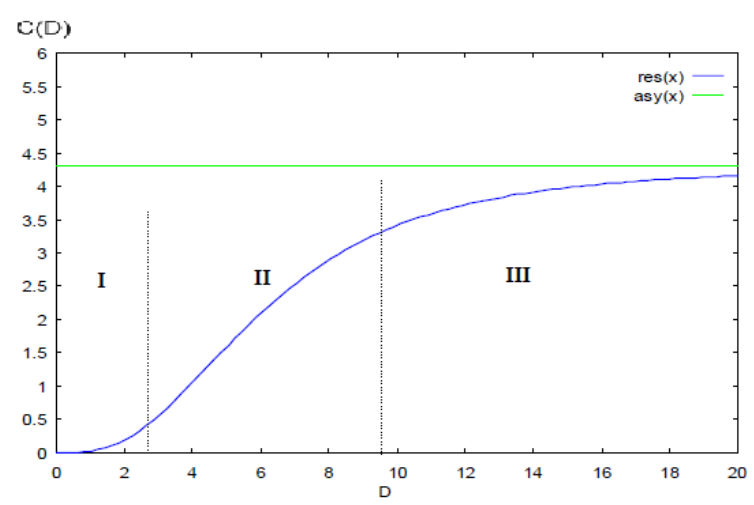

Fig.3. Diagram of the evolution of $\mathrm{C}$ as a function of $\mathrm{D}$.

For the single parameter of quantification, the model is reduced based on the following hypothesis:

$C(D)=0 ; D=0 \quad$ This is the hypothesis I.

$C(D)=C(D) \infty ; D \rightarrow \infty$ This is the hypothesis II.

The magnitude ' $C(D)$ ', this magnitude supposed to continuous a function of the dosage ' $\mathrm{D}$ ' in the following relation:

$C(D)=\frac{a_{D} * D^{n}}{b_{D}+D^{n}}+C_{0}$

\section{Results and Discussions}

This work presents the different results obtained in this study and it aims to show the influence of the different percentages cement content on the thermal conductivity, the specific heat and the evolution of the temperature of the samples CEBs in the dry state. The table 1 shows the results of the thermal conductivity and the specific heat of the four samples with different cement content, the thermal conductivity and specific heat increases with high cement content.
Table1. The results of the Thermal conductivity $(\mathrm{W} / \mathrm{m} . \mathrm{K})$ and Specific heat $(\mathrm{J} / \mathrm{kg} . \mathrm{k})$ with different percentages of cement.

\begin{tabular}{|c|c|c|c|}
\hline The samples & $\begin{array}{c}\text { Dosage of } \\
\text { cement } \\
(\%)\end{array}$ & $\begin{array}{l}\text { Thermal } \\
\text { conductivity } \\
(\mathbf{W} / \mathbf{m} . \mathbf{K})\end{array}$ & $\begin{array}{l}\text { Specific } \\
\text { heat } \\
(\mathrm{J} / \mathrm{kg} . \mathrm{k}) \\
\end{array}$ \\
\hline Sample 1 & 0 & 0,662 & 991,9 \\
\hline Sample 2 & 4 & 0,692 & 1080,9 \\
\hline Sample 3 & 7 & 0,746 & 1205,3 \\
\hline Sample 4 & 10 & 0,785 & 1224,01 \\
\hline
\end{tabular}

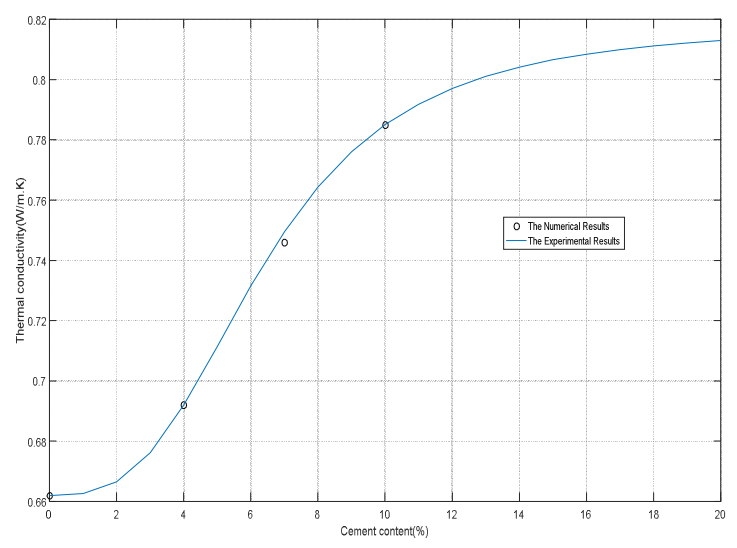

Fig. 4. The thermal conductivity of the samples to increases with an increase in percentage of cement content.

Figure 4 shows experimental and numerical results of the samples CEBs, we can observe that there are three zones as we mentioned in the numerical model. The Induction zone it starts from $0 \%$ to $4 \%$ of cement content, in this zone can observe the effect of stabilization variable is low, due to the low value of the stabilization variable $\mathrm{D}$ (cement content) and therefore does not bring a significant improvement to the magnitude $\mathrm{C}$ (thermal conductivity). The effect zone it starts from $4 \%$ to $7 \%$ of cement content, in this zone can observe the effect of the stabilization is appear clearly, its effect begins to appear and interacts with the samples, and the magnitude $\mathrm{C}$ (thermal conductivity) undergoes a clear improvement as a function of the stabilization variable $\mathrm{D}$ (cement content). And saturation zone it starts from 7\%, in this zone can observe it is beyond a threshold, the magnitude $\mathrm{C}$ (thermal conductivity) is less sensitive to the increase of the stabilization variable $\mathrm{D}$ (cement content), the contribution of the stabilization is not rewarded by a gain on the magnitude $\mathrm{C}$ (thermal conductivity). The experimental results agree with the numerical results, all the experimental results and numerical results illustrate the effect cement content on the thermal conductivity of the samples CEBs in the dry state with $\mathrm{C}_{0}=0.662, \mathrm{a}_{\mathrm{D}}=$ $0.156084598, b_{D}=268.98047$.

The results show that the thermal conductivity of the samples varies according to the cement content, in figure 4 , the curve obtained shows that the thermal 
conductivity varies as a function of the cement content, thermal conductivity of the samples CEBs increase with the increasing of cement content. The thermal conductivity as a function of cement content give nonlinear relation.

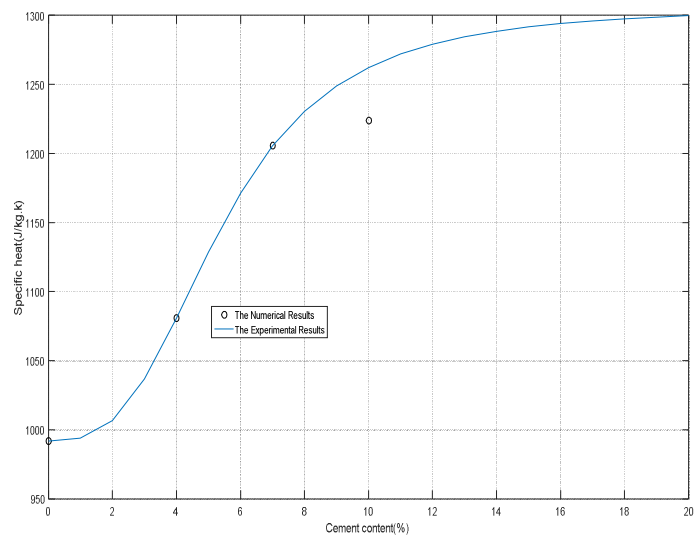

Fig. 5. The specific heat of the samples with different percentage of cement content.

From figure 5 the magnitude $\mathrm{C}$ (specific heat) as function of the stabilization variable $\mathrm{D}$ (cement content), shows the experimental and numerical results of the samples CEBs of the specific heat with different dosage of cement, we can observe also that there are three zones as we mentioned in the numerical model, as in the curve 4, the experimental results agree with the numerical results, all the experimental results and numerical results illustrate the effect cement content on the specific heat of the samples CEBs in the dry state with $\mathrm{C}_{0}=991.9, \mathrm{a}_{\mathrm{D}}=$ $314.115, b_{D}=161.881$.

The term 'specific heat' refers to the heat energy per unit mass (typically $1 \mathrm{~kg}$ ) required to raise the temperature of a substance by one-degree Kelvin, the higher the specific heat capacity of a substance, the more energy is required to raise its temperature, we observed a characteristic increase of specific heat with increase of cement content.

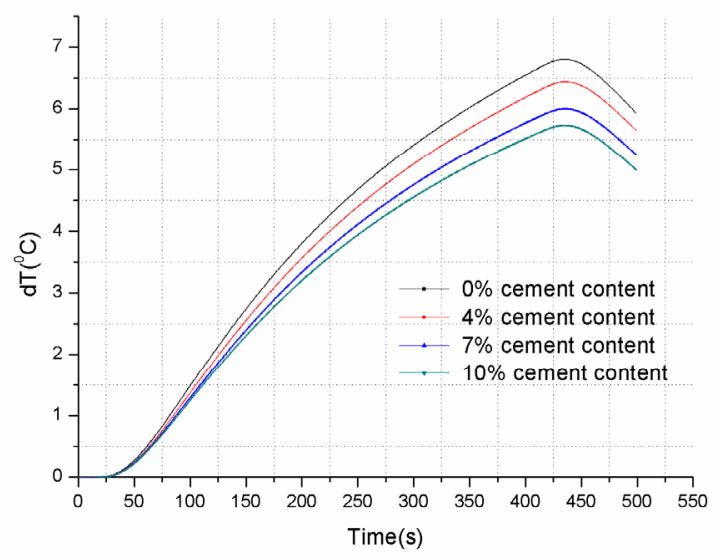

Fig. 6. Evolution of the temperature with time for the samples (dry state) with different percentages of cement $(0 \%, 4 \%, 7 \%$, and $10 \%)$.
The results illustrated on figure 6 show the experimental results, the cement content $(0 \%, 4 \%, 7 \%$ and $10 \%$ ) has effect on the variation of temperature of samples CEBs. We have used the hot-ring apparatus and measured the temperature rise at the center of the ring for each of the CEBs specimens presented. We made temperature rise measurements for the time range 1-500 $\mathrm{s}$, heating time $=400 \mathrm{~s}$ with heating power $\mathrm{Q}=2 \mathrm{~W}$.

From the figure 6 illustrate thermal mass of the samples is the ability of the samples to absorb and store thermal energy of period time, the samples is heated by the slap kapton of the hot ring method, until time of heating, then it stays warm a few seconds, after that the samples start lose the heating.

\section{Conclusion}

The compressed earth block stabilized contribute to the improvement of the energy efficiency in building, especially that compressed earth block stabilized owns low thermal conductivity, and can use it for the thermal isolation of buildings.

This work to estimate the thermal behavior of the compressed earth block stabilized by cement and to evaluate the influence of different dosages of cement on the thermal properties of CEBs.

We can observe through the results obtained that thermal behavior of the samples CEBs in the dry state depended strongly on percentage of cement stabilizer, the thermal conductivity and specific heat of CEBs increases with the increase in the percentage of cement.

Thermal conductivity and specific heat of CEBs decrease without add cement also, the addition of cement further increases the thermal conductivity and specific heat of the CEBs.

The results showed that the decrease in cement percentage lowers thermal properties of the samples CEBs, and on the other hand the increase in cement percentage lead to higher thermal properties of the samples CEBs, when cement add to soil was found increase the specific heat and increase the thermal conductivity of the of the samples CEBs.

The mathematical model is used to describe the evolution of the thermal behavior with cement content, the proposed model is that it was developed in approximations numerical results with experimental results, and we have obtained numerical results agrees with experimental results. In fact, this model allows to determine the technico-economic optimum of stabilization which corresponds to the optimum cement rate to be used for a specific earth material. Indeed, this optimum corresponds to the maximum of the thermal behavior with a minimum of economic investment in the stabilizer (cement in this case).

\section{References}

[1] Jean-Claude Morel, Abalo Pkla, Peter Walker, Construction and Building Materials 21 (2007)

[2] A. Ammari, K. Bouassria, M. Cherraj, H. Bouabid, S. Charif D'ouazzane, Case Studies in Construction Materials 7 (2017). 
[3] Azakine Sindanne S, Ntamack GE, Lemanle Sanga RP, Moubeke CA, Kelmamo Sallaboui ES, Bouabid H, Mansouri K, D’Ouazzane; J. Build. Mater. Struct. 1 (2014).

[4] P. Meukam, Y. Jannot, A. Noumowe, T.C. Kofane, Construction and Building Materials 18 (2004) .

[5] R. Coquard, D. Baillis, D. Quenard, International Journal of Thermal Sciences 47 (2008).

[6] Márcio Buson, Nuno Lopes, Humberto Varum, Rosa Maria Sposto and Paulo Vila Real, fire and materials.Fire Mater. (2012).

[7] M. Cherraj, thèse doctorat, Université Mohammed vAgdal, Faculté des Sciences, Rabat-Maroc.

[8] H. Bouabid, S. Charif d'ouazzane, O. Fassi-fehri, Rapport Interne, CRR-Bâtiment, LPEE, Casablanca, Déc. (1998).

[9] Hayet Khab, Abla Chaker, Séminaire International sur le Génie Climatique et l'Energétique, SIGCLE'2010.

[10] http://earthblockinternational.com/faq/

[11] P. Meukam, A. Noumowe, T.C. Kofane, thermo physical properties of lateritic soil brick, the Abdus Salam internatinal centre for theorical physics, IC/2002/157.

[12] Joseph Khedari, Pornnapa Watsanasathaporn, Jongjit Hirunlabh, Thailand, Received 19 December (2002); accepted 16 February (2004).

[13] Salim Guettala, Mohamed Bachar, Lakhdar Azzouz, .J Earth Sci Clim Change (2016).

[14] Malahimi Anjorin, Chakirou Akanho Toukourou, Aristide Comlan Houngan, Christophe Awanto, Largum Madougou, Journal of Civil Engineering and Architecture 10 (2016) . 